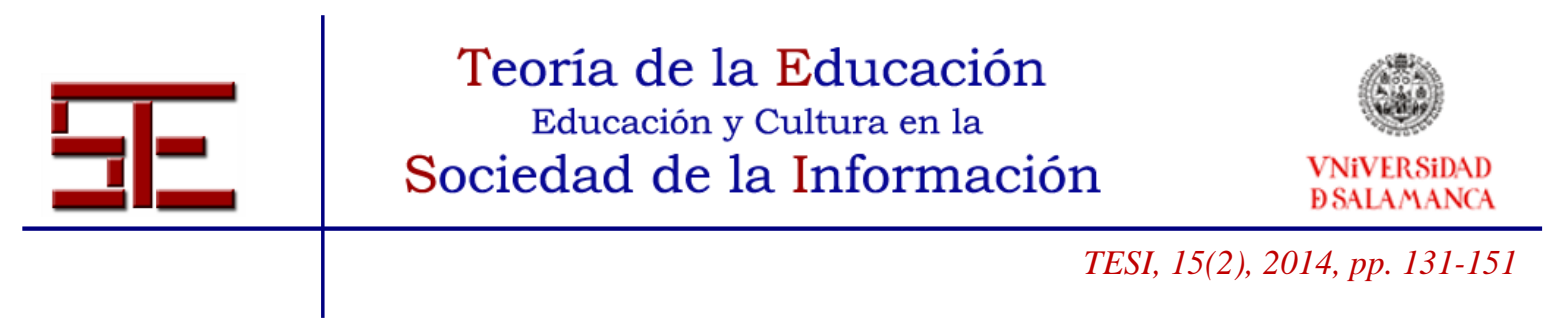

\title{
UNA NUEVA APROXIMACIÓN AL CONCEPTO DE EDUCACIÓN PERSONALIZADA Y SU RELACIÓN CON LAS TIC
}

Resumen: La concepción de la educación personalizada está hoy extendida en numerosos países y contextos educativos. Este trabajo pretende contribuir a clarificar el concepto, estableciendo una relación con las TIC en la actual Sociedad del Conocimiento y de la Información. Tomando como guía la revisión de diversas fuentes y la reflexión sobre actualización del concepto, se propone que educar es ayudar a cada ser humano a establecer y mantener vínculos valiosos con la realidad. Además, se aportan diversas prospectivas para profundizar en estos y otros aspectos.

Palabras clave: Enseñanza personalizada; Tecnologías de la Información y Comunicación (TIC); Sociedad del Conocimiento; Humanismo.

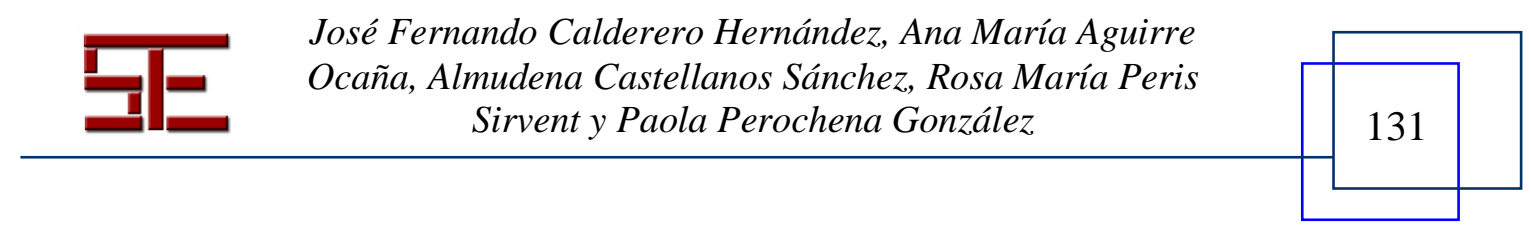




\title{
NEW APPROACH TO THE PERSONALIZED EDUCATION AND ITS RELATIONSHIP WITH THE ICT
}

\begin{abstract}
The concept of personalized education is widely extended in many countries and educational contexts today. This article aims to help clarify this concept and establish its relation to the Information technologies in today's Knowledge and Information Society. Reflecting upon the review of several sources and the recent updating of this concept of education, we understand that to educate is to help every human being to establish and keep valuable links with reality. We also point out several prospectives which might help deepen these and other aspects.
\end{abstract}

Key words: Personalized education; ICT; Knowledge society; Humanism.

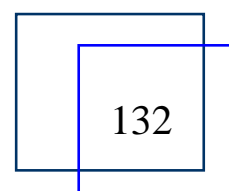




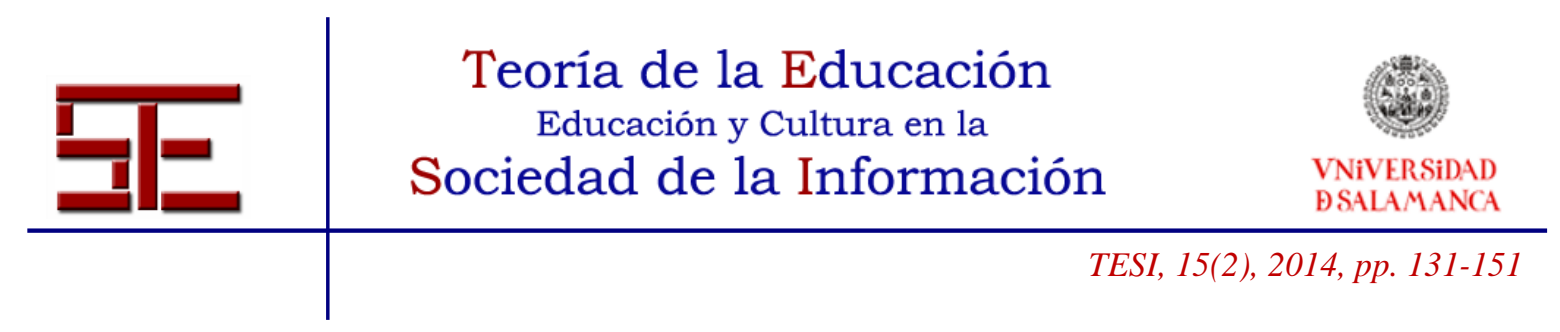

\section{UNA NUEVA APROXIMACIÓN AL CONCEPTO DE EDUCACIÓN PERSONALIZADA Y SU RELACIÓN CON LAS TIC}

Fecha de recepción: 21/03/2014; fecha de aceptación: 19/05/2014; fecha de publicación: 30/06/2014

José Fernando Calderero Hernández

josefernando@unir.net

Universidad Internacional de La Rioja

Ana María Aguirre Ocaña

anamaria.aguirre@unir.net

Universidad Internacional de La Rioja

Almudena Castellanos Sánchez

almudena.castellanos@unir.net

Universidad Internacional de La Rioja

Rosa María Peris Sirvent

rosa.peris@unir.net

Universidad Internacional de La Rioja

Paola Perochena González

paola.perochena@unir.net

Universidad Internacional de La Rioja

\section{1.- INTRODUCCIÓN}

Este trabajo se enmarca en una de las líneas del Proyecto de Investigación I+D: Educación Personalizada en la Era Digital, financiado por la Universidad Internacional de La Rioja dentro de su plan propio de investigación para el bienio 2013-15 y parte de la necesidad de clarificar una de las concepciones pedagógicas que actualmente más presente está tanto en la legislación educativa como en las pedagogías emergentes que han ido surgiendo en la Era Digital, la educación personalizada.

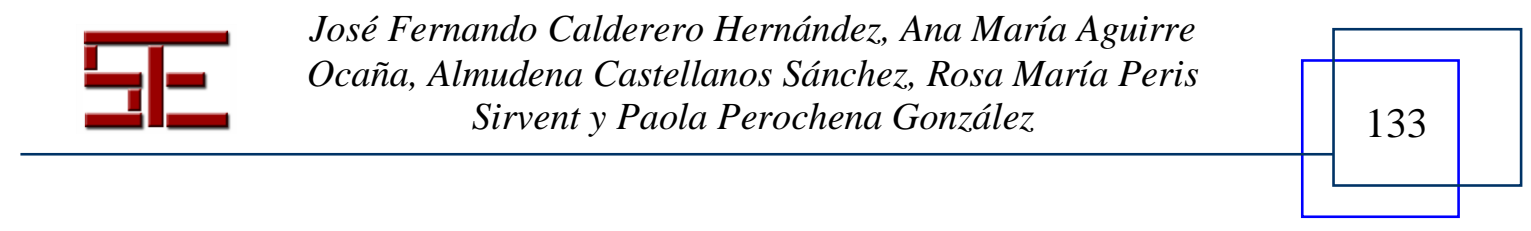




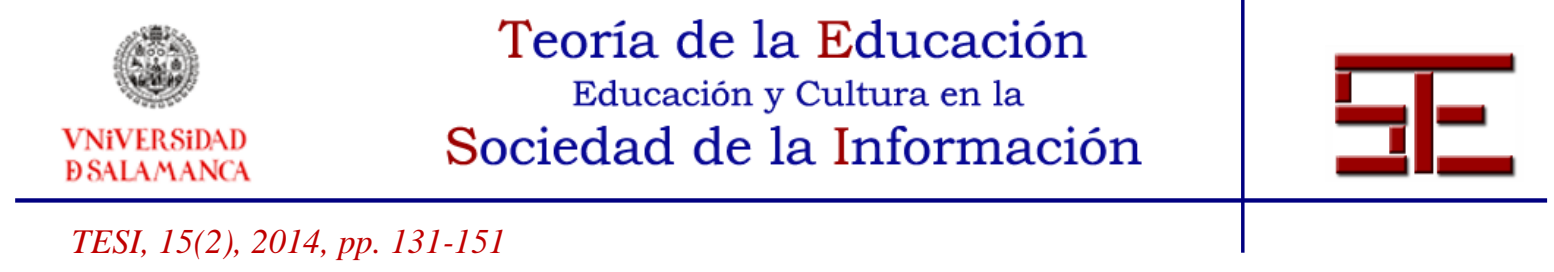

Sin ir más lejos, la reciente Ley Orgánica 8/2013, de 9 de diciembre, para la mejora de la calidad educativa (LOMCE), introduce por primera vez el término educación personalizada en su preámbulo, haciendo referencia a que "nunca como ahora, en plena Sociedad de la Información y el Conocimiento, hemos tenido la oportunidad de disponer de una educación personalizada y universal", sin embargo, ¿qué quiere decir la séptima Ley educativa de la Democracia española con educación personalizada?, ¿qué condiciones se dan en estos momentos históricos que no se hayan dado en otros, que favorecen una educación personalizada?

Por otro lado, estamos asistiendo a una proliferación de experiencias innovadoras que apuestan por nuevas formas de enseñar y aprender flipped classroom, entornos personales de aprendizaje, cursos masivos abiertos online (MOOC), conectivismo... a las que algunos autores han denominado pedagogías emergentes por ser "ideas pedagógicas, todavía no bien sistematizadas, que surgen alrededor del uso de las Tecnologías de la Información y Comunicación (TIC) en educación y que intentan aprovechar todo su potencial comunicativo, informacional, colaborativo, interactivo, creativo e innovador, en el marco de una nueva cultura del aprendizaje". Estas ideas pedagógicas, que solo en cierto sentido podríamos considerar emergentes, tienen en común su aspiración por personalizar la educación, pero ¿qué entienden en este sentido? (Adell y Castañeda, 2012, 15).

La revolución tecnológica del siglo XXI aplicada a la educación está permitiendo por, un lado, flexibilizar los modelos educativos en beneficio de itinerarios formativos personalizados, abrir el material y los contenidos para que sobrepasen las aulas, incluso ofrecer herramientas y servicios que permiten difundir la información con rapidez. El proceso de enseñar y aprender tiende hacia la participación y la colaboración. Los estudiantes adquieren competencias mientras interactúan en los entornos virtuales, gestionando y compartiendo conocimiento, trabajando en equipo a través de los medios telemáticos y alternando la comunicación virtual con la presencialidad. Por otro lado, las tecnologías están permitiendo atender a la singularidad de cada estudiante, dándole un protagonismo que le permite descubrir por sí mismo el conocimiento, decidir los medios que emplea para documentarse y hasta autoevaluar sus aprendizajes, recurriendo en todo este proceso a la tecnología (Fundación Telefónica, 2012).

Este trabajo pretende aportar una actualización del concepto de educación personalizada en la sociedad actual, con los medios y recursos disponibles en la Sociedad y de la Información y el Conocimiento, entre ellos las TIC, para atisbar su potencialidad pedagógico-didáctica.

\section{2.- UNA VISIÓN PANORÁMICA DE LA EDUCACIÓN PERSONALIZADA}

La educación personalizada es una concepción que ha sido abordada por diversos investigadores, pedagogos y profesionales que han aportado teorías y experiencias de

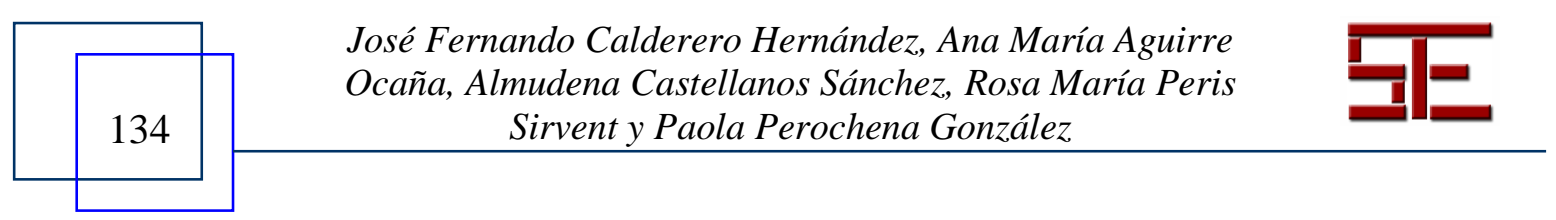




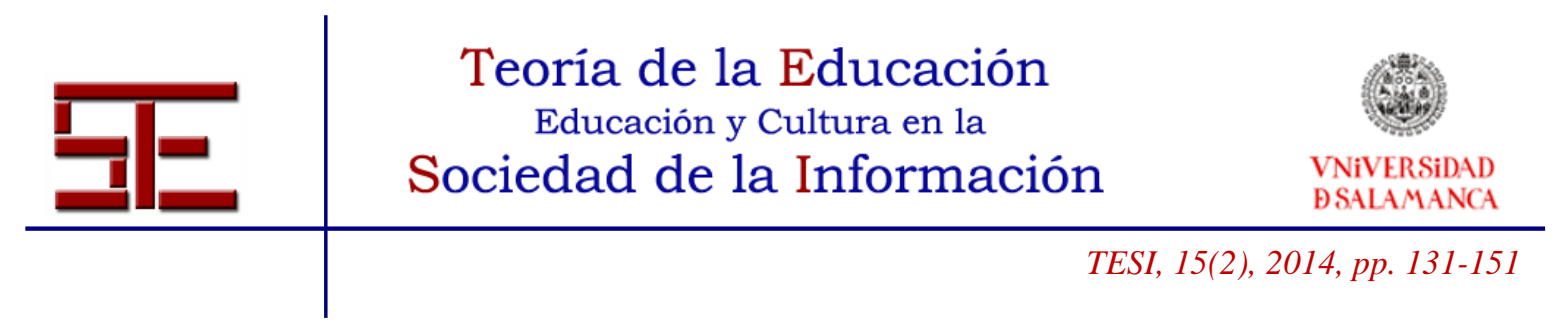

puesta en práctica, relevantes para profundizar en lo que es y en su aplicación. Se mencionan a continuación algunos de ellos, sin pretender agotarlos, a modo de muestra de la repercusión internacional de la educación personalizada.

Claparède, de Ginebra, en su teoría educativa establece que el estudiante tenga la libertad de poder elegir sus actividades, en función de unas tareas ya organizadas previamente por el docente ofreciéndole una autonomía para formarse intelectualmente, social y moral además de alcanzar su desarrollo personal; su base didáctica se basa en una escuela activa. Dottrens (1973) amplía su concepción teórica considerando a la escuela como un medio donde los alumnos se preparan para incorporarse a la sociedad en la que están inmersos (Hofstetter; Schneuwly, 2009).

Parkhurst (EE.UU) concedió una especial relevancia a la individualización de la enseñanza partiendo de que el estudiante fuera reconocido como ser individual y posibilitándole una acción personal para lograr alcanzar sus aprendizajes. Se centró en las bases didácticas de Montessori y en el año 1922, creó un Plan propio, "Plan Dalton", que fue desarrollado en la Escuela de Secundaria de esa misma ciudad; las bases para el aprendizaje son la atención a los diferentes ritmos de trabajo y estilos de aprendizaje. Para ello, se requiere otorgar la capacidad de realizar la programación del plan de estudios y que se sustente en las características individuales, concediendo autonomía, e incentivando el desarrollo de las habilidades y de ejercer responsabilidades con respecto a la comunidad de estudiantes. El método didáctico que desarrolla para favorecer un aprendizaje individual consiste en organizar laboratorios en vez de cursos, establece un contrato formal de tareas entre el discente y el docente desde el currículo oficial (Van der Ploeg, 2013).

Washburne, coterráneo de Parkhurst, es creador del denominado "Plan Winnetka" en 1922. En su teoría didáctica menciona la necesidad de que el docente favorezca al alumno en su proceso de aprendizaje, con una programación en unidades temáticas, considerando su edad cronológica y sus conocimientos adquiridos. Además, en su práctica educativa, incorpora actividades creativas y la preocupación por el desarrollo emocional y social. Desde esta perspectiva ya desarrolla también un perfil comunitario en la persona como es propio de la educación personalizada (Uyeda, Luft, Madden, Washburne y Brigham, 2003).

En la misma línea, Keller (citado en Harzem, 1996), junto con profesores de otras universidades entre ellos Sherman, Azzi y Bori, desarrollaron un Sistema de Instrucción Personalizada, para favorecer el aprendizaje de los discentes y que puede ser considerado como un cierto avance en la educación personalizada, porque se requiere integrar todas las dimensiones del estudiante: experiencias emocionales y sociales, no sólo las cognitivas. Su base metodológica reside fundamentalmente en que el profesor organiza los contenidos de aprendizaje del curso, dividiéndolos en unidades didácticas o temáticas describiendo el objetivo principal a alcanzar. Incluye en su modelo, al igual

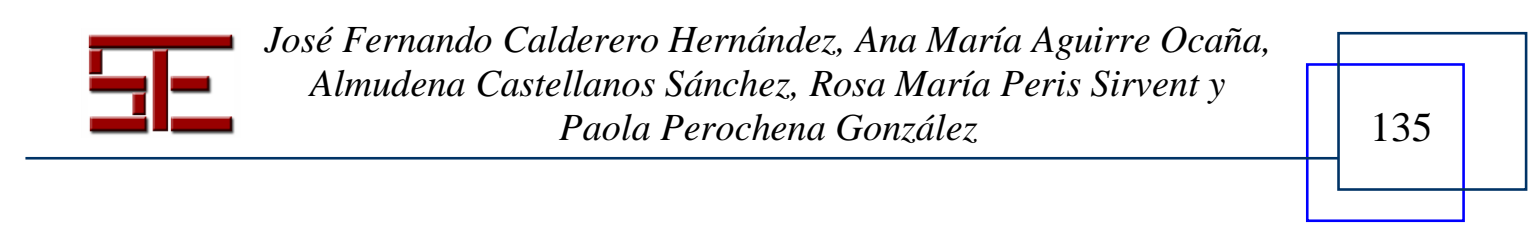




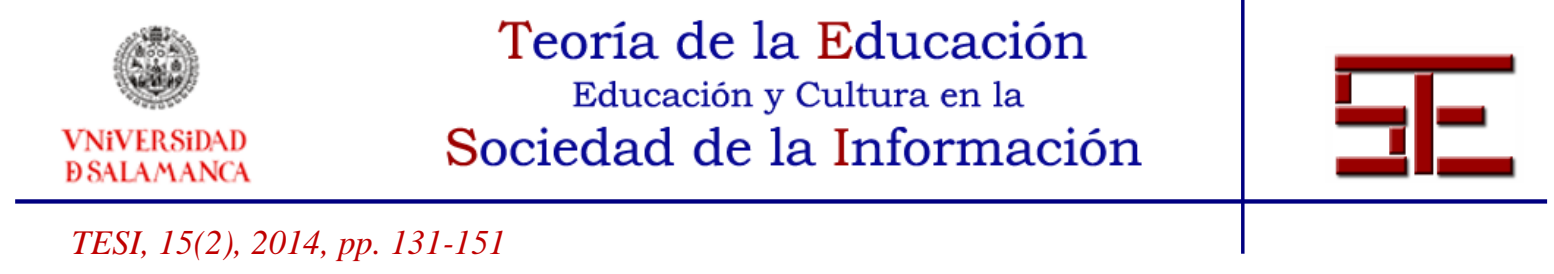

que los primeros autores, el respeto al ritmo de aprendizaje del alumno y la incorporación de un guía asesor que oriente en ese proceso, reforzando y resolviendo las dudas que le surjan.

En Francia, Faure introduce una pedagogía personalista (citado en Pereira de Gómez, 1981). De ahí surgen los supuestos de su estrategia educativa, que se centran en los aspectos personales del alumno fundamentalmente: que realice una toma de conciencia de su persona, que muestre una capacidad de respuesta libre y personal, que sepa descubrir los valores y la capacidad de compromiso y que los asuma personalmente. Concibe la didáctica desde una pedagogía que implica la totalidad del ser, la totalidad de la persona. Desde esta perspectiva, la educación que se realiza en la práctica del aula requiere que el docente tenga una buena actitud y conocimiento del estudiante, que establezca un clima afectivo, una organización de la clase y que haya una integración de la vida en la labor de la escuela.

En el ámbito educativo español, su representación continuada es García Hoz. Entre las abundantes contribuciones a la concepción de la educación personalizada destaca principalmente, la especial relevancia a la acción del educando, de manera que su formación recae en la aceptación de sus responsabilidades. Enfatiza en la preparación para ser más eficaz para la sociedad. La práctica educativa, el conocimiento, los estilos cognitivos y de aprendizaje, así como mostrar un carácter integrador, estar abierto a la comunicación, permiten la reflexión y la creatividad. Hacer demostración de optimismo en la práctica diaria y atender al ser "singular", pero al mismo tiempo facilitar la relación de la comunidad constituyen pilares fundamentales de la educación. García Hoz sugiere también utilizar la tecnología en la educación personalizada, dando especial relevancia a los métodos, las técnicas como recurso metodológico y el uso de la tecnología informática (García Hoz, 1988).

Entre las aportaciones de autores ingleses, Peters, cuya obra está más cerca de la filosofía de la educación, presenta dos aportaciones importantes en el ámbito educativo, relacionadas ambas con los factores técnicos que posibilitan la educación personalizada, término utilizado por Bernardo (2011), como son: esclarecer conceptos y términos de educación, enseñar, entrenar, adoctrinar y acondicionar, y concebir una teoría de la educación valorando el pensamiento educativo. Como se recoge en Bowen y Hobson (1979), uno de los aspectos más interesantes de Peters es la definición sobre la educación. La concibe como un proceso en el que el profesor tiene que hacer uso de los métodos y dotar los recursos suficientes para que el alumno desarrolle en sus aprendizajes tanto los conocimientos como la comprensión de los mismos, de una forma organizada y donde se perciba una voluntad de acción en el educando.

En Argentina, dos autoras, Vázquez y Nuttin. Vázquez integran el concepto de alumno como persona y menciona la importancia que tiene el proceso de integración de la personalidad en el sujeto donde lo primero que se requiere es la aceptación íntima de sí

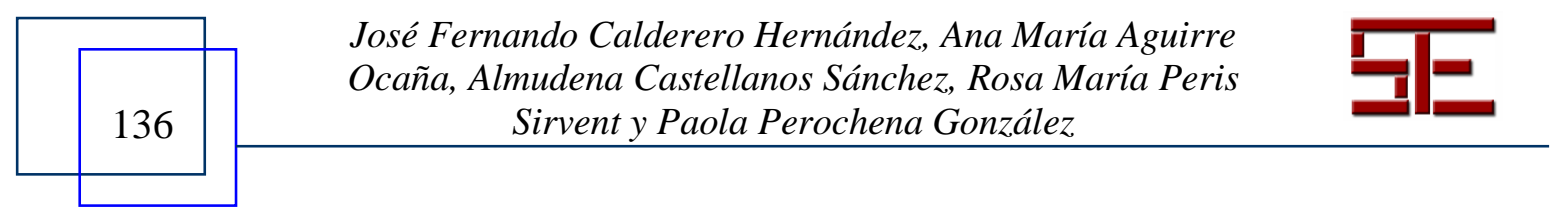




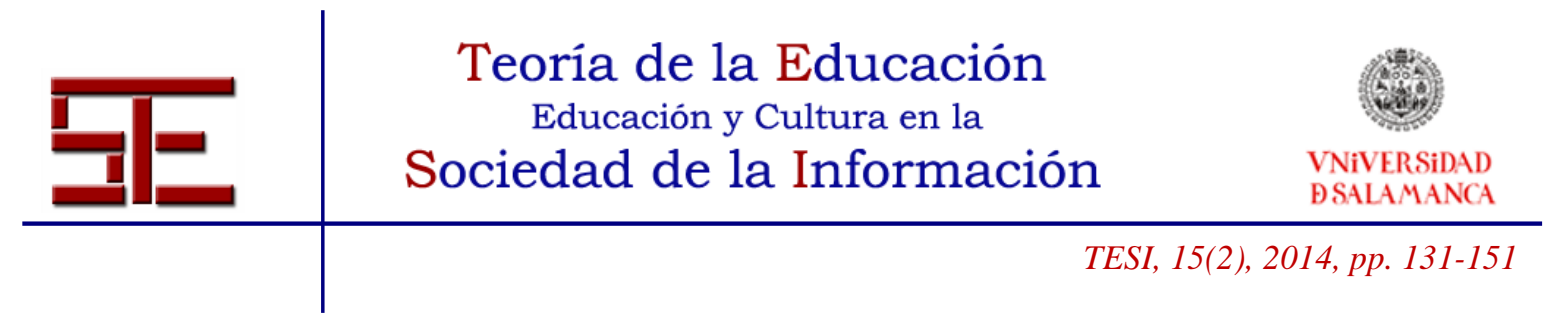

mismo, del conjunto de las capacidades propias, así como de las carencias y limtaciones; a partir de ello el sujeto puede iniciar un camino de desarrollo normal (Vázquez, 2000). Nuttin (1972) mantiene que se desarrolla construyendo "la socialización de la personalidad", en la que el estudiante proyecta sus posibilidades en la sociedad y en la cultura donde se integra. En su teoría de la enseñanza, se obtiene el perfil del educador en base a dos objetivos principales: ser un guía para desarrollar el proceso de autoconocimiento del alumno permitiéndole conocer su singularidad y que pueda asumir su libertad relacionándola con su fin último personal $\mathrm{y}$, desde otra función, el educador tiene como responsabilidad el acrecentar el desarrollo de virtudes que faciliten al alumno una autonomía para lograr el proceso de integración personal (Vázquez, 2000). Fundamentalmente su concepción se basa en el desarrollo del carácter interior de la persona, para configurar su personalidad. Finalizaremos con Daura, que reside actualmente en Buenos Aires. Su pedagogía se basa principalmente en la necesidad de que los docentes universitarios utilicen unas estrategias didácticas personalizadas y que los estudiantes tienen que desarrollar un aprendizaje autorregulado. "El aprendizaje se concibe como un proceso propio de la persona humana en el que se disciernen, asimilan y transfieren conocimientos, valores y hábitos, posibilitando el desarrollo integral de la personalidad y la modificación de la conducta individual y social" (Archideo, 1996, citado en Daura, 2012, 52). Otro de los aspectos a destacar de su obra es la relevancia que otorga a la función tutorial formando parte de la educación personalizada y del proceso de autorregulación.

A modo resumen aportamos la siguiente tabla (Tabla 1) que recoge algunos de los autores que hemos comentado.

TABLA 1. Autores que han aportado teorías en torno a la educación personalizada

\begin{tabular}{|c|c|c|c|}
\hline Autor & Año & País & Aportación Principal \\
\hline $\begin{array}{l}\text { Claparède, } \\
\text { Edouard }\end{array}$ & $\begin{array}{l}(1873- \\
1940)\end{array}$ & Suiza & $\begin{array}{l}\text { Promueve la elección libre de actividades para } \\
\text { mejorar el crecimiento intelectual, social y } \\
\text { moral, y desarrollar plenamente la personalidad } \\
\text { del discente. }\end{array}$ \\
\hline $\begin{array}{l}\text { Parkhurst, } \\
\text { Helen }\end{array}$ & $\begin{array}{l}1886- \\
1973\end{array}$ & $\begin{array}{l}\text { Wisconsin } \\
\text { (EE.UU) }\end{array}$ & $\begin{array}{l}\text { Considera el aprendizaje del alumno como un } \\
\text { proceso individual, respetando la actividad } \\
\text { personal del niño. }\end{array}$ \\
\hline $\begin{array}{l}\text { Washburne, } \\
\text { Carleton W. }\end{array}$ & $\begin{array}{l}(1889- \\
1968)\end{array}$ & Chicago & $\begin{array}{l}\text { Es pionero en la enseñanza individualizada y } \\
\text { educación personalizada. Introduce actividades } \\
\text { creativas, actividades en grupo, foros abiertos, } \\
\text { y valora las dimensiones emocional y social del }\end{array}$ \\
\hline
\end{tabular}

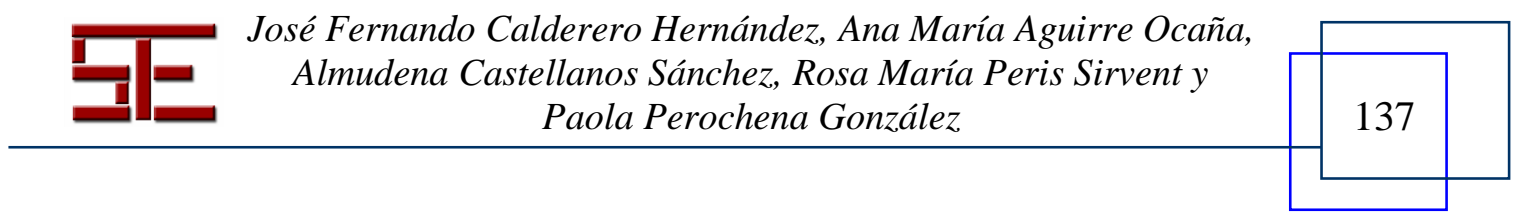




\begin{tabular}{|c|c|c|c|}
\hline 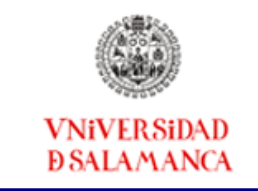 & \multicolumn{3}{|c|}{$\begin{array}{l}\text { Teoría de la Educación } \\
\text { Educación y Cultura en la } \\
\text { Sociedad de la Información }\end{array}$} \\
\hline \multicolumn{4}{|c|}{ TESI, 15(2), 2014, pp. 131-151 } \\
\hline & & & alumno. \\
\hline $\begin{array}{l}\text { Keller, Fred } \\
\text { S. }\end{array}$ & $\begin{array}{l}(1889- \\
1996)\end{array}$ & EEUU & $\begin{array}{l}\text { Desarrolla un Sistema de Instrucción } \\
\text { Personalizada (SIP), cada estudiante avanza a } \\
\text { su propio ritmo, siendo apoyado por un guía } \\
\text { asesor que aclara dudas, refuerza contenidos y } \\
\text { orienta sobre formas de estudio. }\end{array}$ \\
\hline Faure, Pierre & $\begin{array}{l}(1904- \\
1988)\end{array}$ & Francia & $\begin{array}{l}\text { Ofrece una visión de pedagogía personalista } \\
\text { pero a la vez comunitaria, aportando unas } \\
\text { estrategias educativas. }\end{array}$ \\
\hline $\begin{array}{l}\text { García Hoz, } \\
\text { V. }\end{array}$ & $\begin{array}{l}(1911- \\
1998)\end{array}$ & España & $\begin{array}{l}\text { Utiliza el término Persona y da una especial } \\
\text { relevancia al papel activo del alumno en su } \\
\text { formación y a los Estilos cognitivos y de } \\
\text { aprendizaje. Promueve el uso de la tecnología } \\
\text { educativa y de la tecnología informática. }\end{array}$ \\
\hline Peters, R.S. & 1919 & Inglaterra & $\begin{array}{l}\text { Esclarece conceptos educativos y valora el } \\
\text { pensamiento educativo. }\end{array}$ \\
\hline $\begin{array}{l}\text { Goodlad, } \\
\text { John }\end{array}$ & 1920 & $\begin{array}{l}\text { Columbia } \\
\text { Británica }\end{array}$ & $\begin{array}{l}\text { Describe la educación como un proceso en el } \\
\text { que hay que desarrollar una libertad de } \\
\text { pensamiento y de acción. }\end{array}$ \\
\hline $\begin{array}{l}\text { Vázquez, } \\
\text { Stella Maris }\end{array}$ & 1945 & Argentina & $\begin{array}{l}\text { Objetivos para un educador: ser un guía para } \\
\text { desarrollar en el alumno su propio } \\
\text { conocimiento personal, psicológico y moral, y } \\
\text { favorecer el desarrollo de sus virtudes para } \\
\text { incorporarse en la sociedad. }\end{array}$ \\
\hline $\begin{array}{l}\text { Daura, } \\
\text { Florencia } \\
\text { Teresta }\end{array}$ & 1979 & Argentina & $\begin{array}{l}\text { Los docentes universitarios tienen que utilizar } \\
\text { unas estrategias didácticas personalizadas; y } \\
\text { los estudiantes tienen que desarrollar un } \\
\text { aprendizaje autorregulado. }\end{array}$ \\
\hline
\end{tabular}

Fuente: Elaboración propia

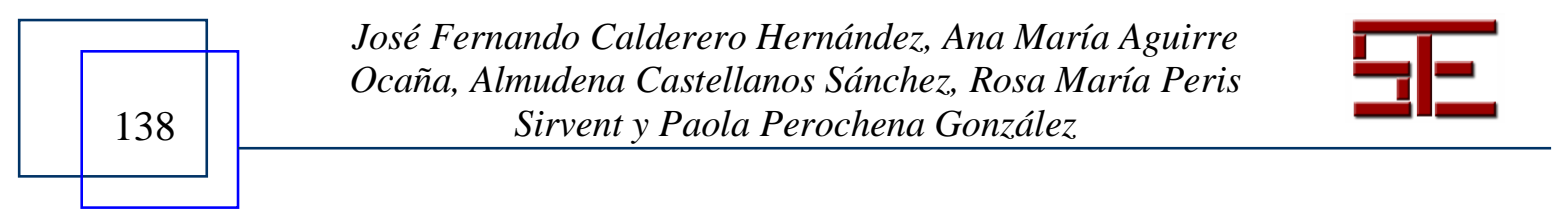




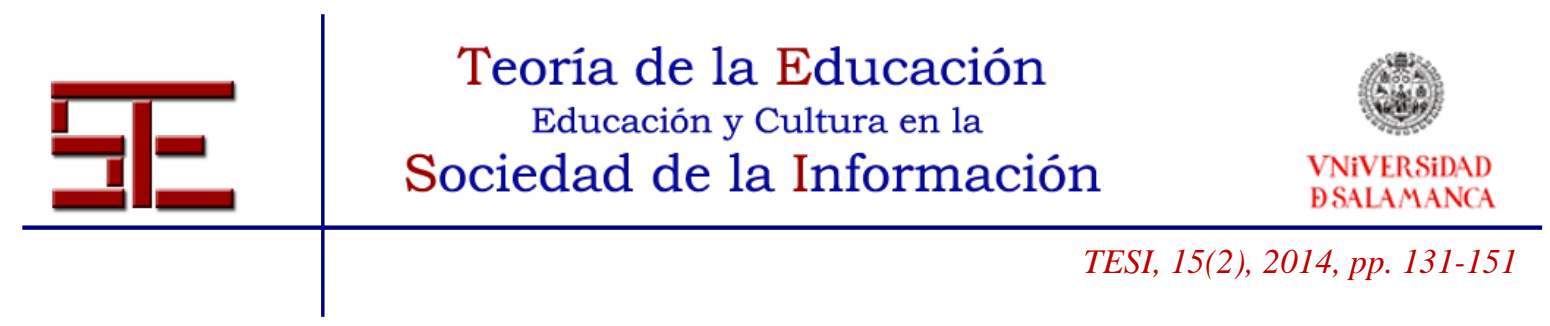

\section{3.- UNA APROXIMACIÓN AL CONCEPTO DE EDUCACIÓN PERSONALIZADA}

La estimulación del sujeto hacia el perfeccionamiento de la capacidad de dirección de la propia vida constituye el propósito fundamental de la educación personalizada; esto significa la efectividad de la libertad personal para participar en la vida comunitaria (Bernardini y Soto, 1984).

Para comprender de modo análogo el concepto de educación personalizada, parafraseando al filósofo clásico Plotino, Domínguez (2002) indica que cada persona es responsable de "esculpir su propia estatua", de construir su biografía y modos para relacionarse. Pero la persona no se forja a sí misma, no emerge en plenitud por sí sola, sino que requiere interacción con el medio. Nos situamos ante dos polos que conforman el ser personal: las propias posibilidades y las propias limitaciones. Las primeras pueden ser capacidades, virtudes, creatividad... mientras que las segundas se relacionan con el sufrimiento, la muerte, la miseria... es necesario actuar de modo realista frente a ambos. Más que el ilustrado extremo de buscar en exclusiva el saber o el hedonista vivir para disfrutar o el economista para tener, la finalidad sería "construir la propia estatua" (Ayala, 2006).

Consideramos que concebir que la persona (y, por tanto, el estudiante) es un ser que investiga, que explora, que se interesa por averiguar sobre aquello que le rodea de modo activo y que no solo reacciona ante los estímulos desde el punto de vista biológico es una de las principales aportaciones de la educación personalizada en general, muy necesaria en el actual contexto educativo de la Era Digital, donde "la institución, en el desempeño de su competencia formadora, debe trabajar con la persona aquellos aspectos que le permitirán vivir en una sociedad en constante cambio" (Torres, 2011, 226); hemos de dar respuestas al estudiante para profesiones que hoy en día existen y para otras que aparecerán a lo largo de su vida, capacidad de aprender y desaprender para adaptarse a los requerimientos de la sociedad.

Personalizar es tanto como referirse a una persona. Siguiendo la exposición de Maritain (1965), podemos afirmar que únicamente una educación integral es personalista en tanto que se ocupa esencialmente del desarrollo de la libertad y de la responsabilidad de la persona, de sus derechos y obligaciones como ser humano, de su participación comunitaria por el trabajo, de su vínculo con la trascendencia; es decir, con todo aquello que está, de algún modo "fuera de ella".

"La educación personalizada lo es en la medida en que se realiza en un sujeto que tiene rasgos propios, que se siente obligado, comprometido, por sus posibilidades personales y que, al mismo tiempo, se ennoblece por el hecho mismo de vivir y obrar como persona" (García Hoz, 1988, 25).

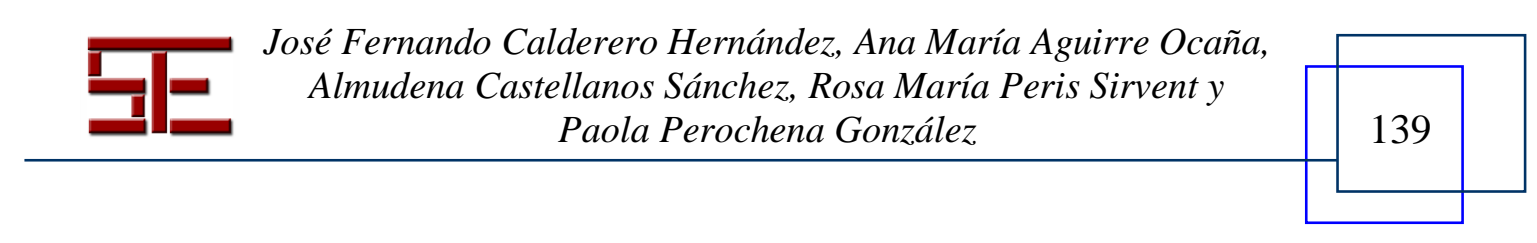




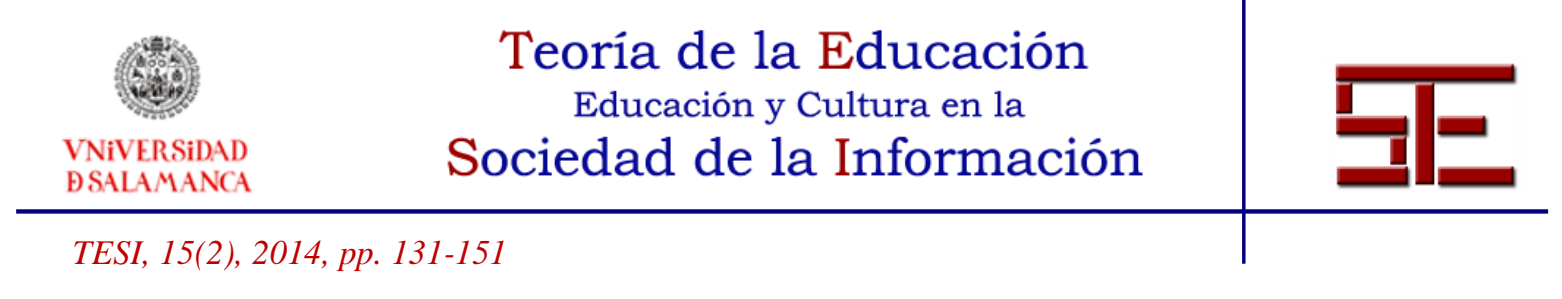

Tres aspectos fundamentales van a regir esta conceptualización educativa, desde el punto de vista de García Hoz (1988): singularidad, autonomía y apertura.

\section{1.- Singularidad}

Constitutiva de la esencia de la persona es la singularidad, que implica no sólo separación real y diferenciación numérica, sino distinción cualitativa en virtud de la que cada hombre es quien es, diferente de los demás. Es un requisito para existir como realidad (Medina, 1989).

La singularidad de cada persona se refiere no a la esencia del hombre, que es la misma en todo ser humano, sino a las partes integrantes que vienen a unirse a las esenciales no para constituir el ser, sino para constituirle de un modo determinado. La educación personalizada se nos presenta como educación integral no en el sentido vulgar de la palabra -como suma de distintas actuaciones educativas- sino, en su significación profunda, como enriquecimiento y unificación del ser y la vida humana.

"Desde el punto de vista de la singularidad personal, el objetivo de la educación es hacer al sujeto consciente de sus propias posibilidades y de sus propias limitaciones" (Consejo Superior de Investigaciones Científicas, 1981, 13), cuantitativa y cualitativamente consideradas unas y otras. Y como la vida del hombre se realiza no sólo en su interior, sino también en relación con el mundo que le rodea, es obligada una futura instancia a este mundo para que el conocimiento de uno mismo sea susceptible de una utilización práctica en el ámbito de la prudencia. La orientación tiene aquí su fundamento más claro.

La consideración de que una persona ha "originado" algo es la manifestación de la singularidad. En la medida en que el origen de alguna realidad está en la actividad de un ser se atribuye a éste la cualidad de creador. Ser original es tanto como ser creador; originalidad y creatividad se hallan estrechamente vinculadas, si es que no son la misma cosa.

\section{2.- Autonomía}

En virtud de la autonomía, la persona es, de algún modo, principio de sus propias acciones. La autonomía confiere una peculiar dignidad según la cual el hombre se siente sujeto, es decir, realidad distinta y superior al mundo de puros objetos que le rodean (Valverde, 1993). "La máxima expresión de la autonomía, a la que justamente hace referencia su significación etimológica, es la capacidad de gobierno de sí mismo, ser ley de sí mismo, la posesión y uso efectivo de la libertad" (García Hoz, 1988, 34).

La capacidad de elección es una manifestación de la educación de la libertad. Enseñar a elegir o educar para elegir bien es un objetivo preciso de la educación personalizada. En palabras de Medina (1989, 19-20), "la clave última y esencial del concepto de educación es la libertad y la decisión personal. A fin de cuentas, la educación no es otra

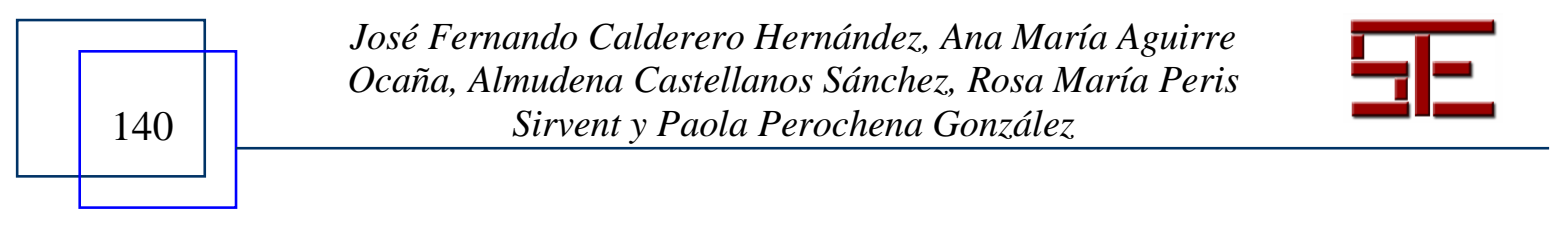




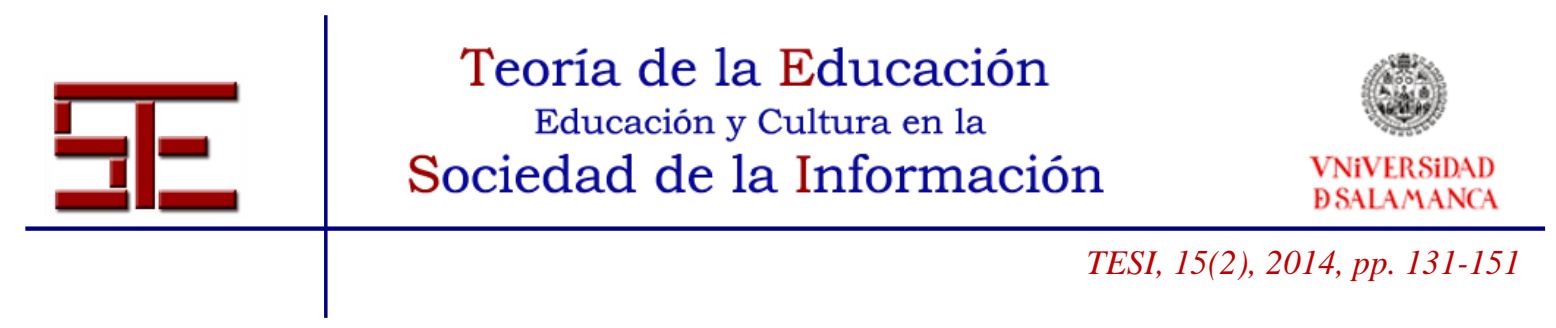

cosa sino un proceso de estímulo y ayuda social, en la vida de cada persona singular... para que sea capaz de autogobernarse o desplegar sus posibilidades de proyectar y decidir, autónoma y responsablemente".

\section{3.- Apertura}

En la persona se realiza la paradoja de una incomunicabilidad absoluta en el ser y al mismo tiempo una necesidad existencial de apertura a los otros. He aquí otro rasgo del que se desprende una madeja de objetivos en la educación personalizada.

En primer lugar, se encuentra con unas relaciones que le vienen impuestas por la existencia de otros sujetos con los que ha de convivir (trabajo, vida social...). En segundo lugar, están las relaciones familiares que no se dan en otra comunidad, por una parte, y, por otra, a medida en que el hombre va evolucionando, es capaz de proyectarse a una familia constituida sobre la base de decisiones propias. Las relaciones familiares presentan como ninguna la necesidad de una libertad de aceptación y posteriormente de una libertad de elección. Hay un tercer tipo de relaciones sociales que responden totalmente a la espontaneidad del hombre respecto de las cuales se mantiene libre de una manera constante: son las relaciones de amistad, el espontáneo fluir de la vida en compañía.

La apertura a la realidad (natural, social y trascendente), como señala Bernardo (2011), se realiza mediante la unificación del trabajo escolar en el desarrollo de la capacidad de comunicación. En esta misma línea, Cortina $(2003,50)$ nos habla de la apertura como "aumentar el nivel de competencia de las personas para poder ponerla al servicio de otros".

Consideramos relevante señalar que la dimensión, o característica, humana de "apertura" no tiene solamente el carácter utilitario de estrategia, o "herramienta", que contribuye a la cohesión social, sino que es una necesidad imperativa de cada ser humano por lo que nos atrevemos a expresar nuestra visión, que en futuros trabajos podríamos desarrollar, de que las metodologías operativas y participativas tienen una gran importancia, más allá de su eficiencia pedagógica.

Se confunde personalización con individualización o atención individualizada. Es una muestra de lo que podríamos llamar la «pedagogía de la simplicidad», opuesta a la «pedagogía de la complejidad» que reclamamos algunos (Pujolas, 2010, 10).

Gimeno $(2000,34)$ trata la pedagogía de la complejidad como "una estructura educativa capaz de enseñar con un alto nivel intelectual en clases que son heterogéneas desde el punto de vista académico, lingüístico, racial, étnico y social, de forma que las tareas académicas puedan ser atractivas y retadoras".

Referirnos a la educación personalizada es tanto como indicar el proceso de personalización en que consiste el fin de la actividad educativa. Carece de sentido

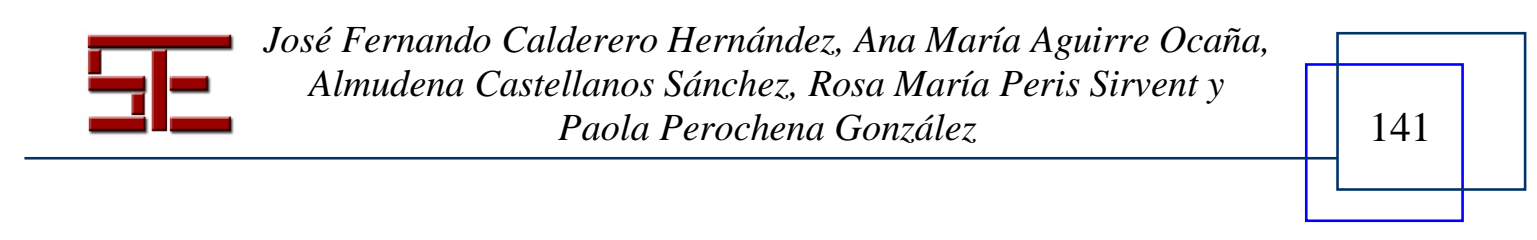




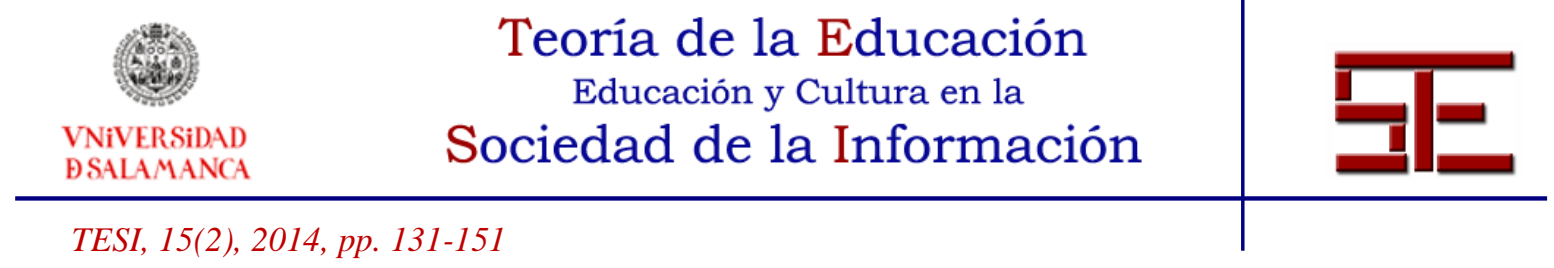

entablar un discurso pedagógico personalista sobre la escuela de masas o sobre el "alumno medio", en ambos supuestos se relega al olvido la propia personalización para pasar a primer plano lo cuantitativo o abstracto (Bernal, 1993).

\section{4.- LAS TIC EN LA EDUCACIÓN PERSONALIZADA}

A pesar de todos los avances conseguidos desde el punto de vista tecnológico, que hacen posible, por un lado, que la educación se abra a la realidad que la rodea, permitiendo un aprendizaje participativo, colaborativo, en comunidad, que atienda a las necesidades sociales, y, por otro, que la educación se ajuste a las necesidades y características individuales de cada persona, en la actualidad siguen dándose formas de abordar la educación tradicionales en las que nada de esto ocurre y en las que las tecnologías son utilizadas simplemente como recurso para apoyar las explicaciones del profesor (Fundación Telefónica, 2012).

Sin embargo, cada vez más somos partícipes de experiencias educativas que apuestan acertadamente por poner en el centro de sus acciones al estudiante, dándole un protagonismo que le permite llegar por sí mismo al conocimiento ayudándose de las tecnologías, eligiendo las herramientas que desea emplear para buscar información, para sintetizarla, para editarla, incluso para publicarla (Adell y Castañeda, 2012). Algunas claves teóricas y metodológicas sobre el uso de las TIC para apoyar el progreso educativo del estudiante para emprender acciones de mejora se tienen en González y Rodríguez (2010). Entre estas, se marcan algunas estrechamente vinculadas con la educación personalizada como son: los intereses personales, la inclusión de grupos colaborativos, las emociones, la interacción, el aprendizaje continuo y contextualizado, entre otras. En ambos modelos expuestos, tradicional y moderno, se entiende el aprendizaje como un proceso individual, sin embargo, no podemos olvidar que, como hemos visto, la tarea de educar lleva siempre implícito el concepto de persona y esta es un ser singular, individual, pero también es un ser social y en su perfeccionamiento juega un papel clave la comunidad. En este sentido, cada vez más están surgiendo movimientos que apuestan por la conectividad y por el aprendizaje en comunidad para construir conocimiento. Estos nuevos modelos que se están introduciendo con fuerza en los centros educativos más innovadores entienden la figura docente como la responsable de diseñar los entornos que favorezcan el aprendizaje y aprovechan la tecnología como mediadora en la construcción del conocimiento y la interacción social (Fundación Telefónica, 2012).

Algunos ejemplos acerca de cómo personalizar la educación con apoyo de las TIC son las recientes aulas invertidas o flipped classroom (Hamdan, McKinight, McKinight y Arfstrom, 2013), en las que el estudiante aprovecha las horas presenciales para las tareas más activas, como ser orientado por el profesor, trabajar en equipo, resolver dudas, compartir descubrimientos con los compañeros o hacer ejercicios y recurre a la virtualidad para cuestiones menos activas como son el visionado de vídeos, las

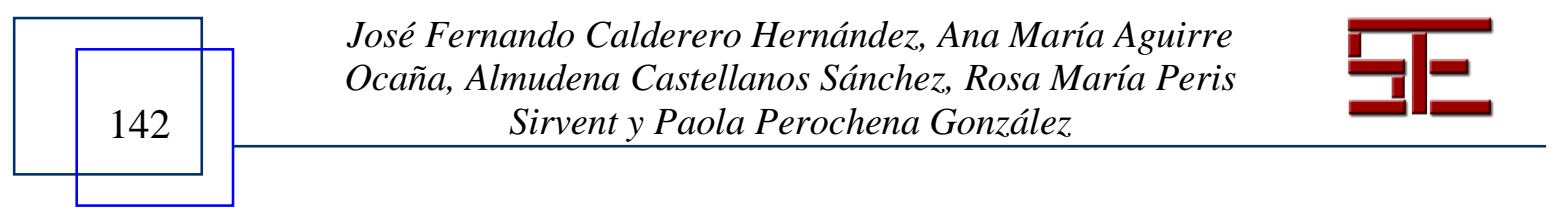




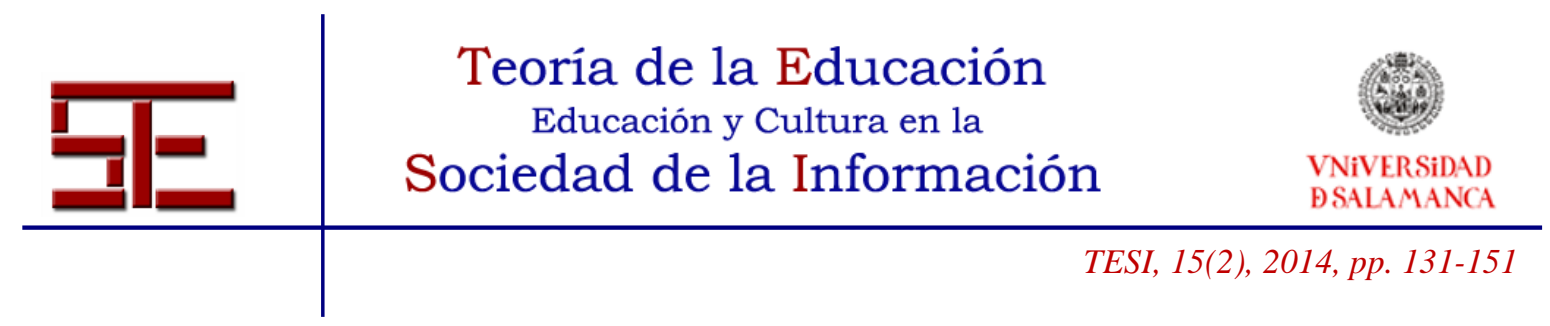

explicaciones de contenidos temáticos, presentaciones, etc. Si bien los estudios que avalan esta práctica no son numerosos, sí existen algunas investigaciones que recientemente están siendo divulgadas acerca de las ventajas de este modelo pedagógico. Un ejemplo es el de la Universidad Estatal de San José, el Centro Universitario Vanderbilt, la Universidad Estatal de Montana (Walsh, 2013) o la Universidad Estatal de California (Hamdan et al., 2013). En España, la Universidad de La Rioja (UR) está llevando a cabo un proyecto - http://www.theflippedclassroom.es/ con los alumnos de los Grados de Maestro Infantil y Primaria que finalizará en junio de 2014, a través del cual pretenden invertir las clases de tal forma que, aprovechando la tecnología móvil y las herramientas colaborativas que ofrece Internet, se pueda dar la vuelta al modelo tradicional de enseñanza. En la Universidad de Murcia (UMA) también se ha llevado a cabo una experiencia en este sentido, en el Grado de Educación Primaria, donde los estudiantes han sido los propios creadores de los contenidos utilizando el medio audiovisual (Gutiérrez, Castañeda y Serrano, 2013); el estudiante es aquí el protagonista en el aprendizaje y ejerce su libertad partiendo de la dimensión individual e integrándola en la social.

Otra clara representación a la hora de personalizar la educación son los entornos personales de aprendizaje (PLE), término recientemente incluido en los ambientes educativos, que definen Adell y Castañeda (2010) como "una idea pedagógica, como una práctica de las personas para aprender valiéndose de la tecnología. Pero sobre todo se entiende como una forma de ver el aprendizaje con la Internet, sus relaciones, dinámica y naturaleza", así consideramos que son entornos para aprender y que incluyen por tanto personas de referencia, herramientas y servicios de lectura, de reflexión, de comunicación... con la que conformamos nuestra red personal de aprendizaje.

En este sentido, los PLE trascienden la mera tecnología y pasan a ser también un compendio de relaciones personales que hacen posible que se produzca el aprendizaje. Son una excelente herramienta para propiciar los encuentros interpersonales (García y Álvarez, 2008), con una faceta individual (la persona elige sus servicios favoritos, publica sus ideas, gestiona sus documentos...) y una faceta social que le permite aprender de los que le rodean por modelaje y con los que le rodean a través de proyectos comunes. Como puede advertirse no habrá dos PLE iguales pues son personales, dependen del estilo educativo de cada individuo, de sus gustos, necesidades, contactos sociales... Construir uno implica conocerse a uno mismo, buscar, elegir, analizar, decidir, comunicar, debatir, compartir..., un buen método sin duda de enseñar a nuestros alumnos a "aprender a aprender" y a perfeccionarse (Castellanos, 2013).

Existe en la actualidad una tendencia social a la hibridación entre lo presencial y lo virtual, de lo físico y lo digital, una tendencia a la organización en grupos sociales con objetivos comunes, al gusto por lo personalizado, por la experimentación y por la

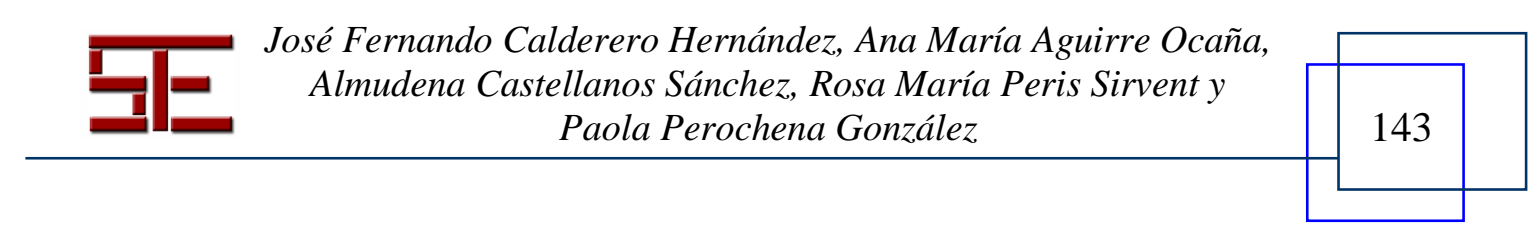




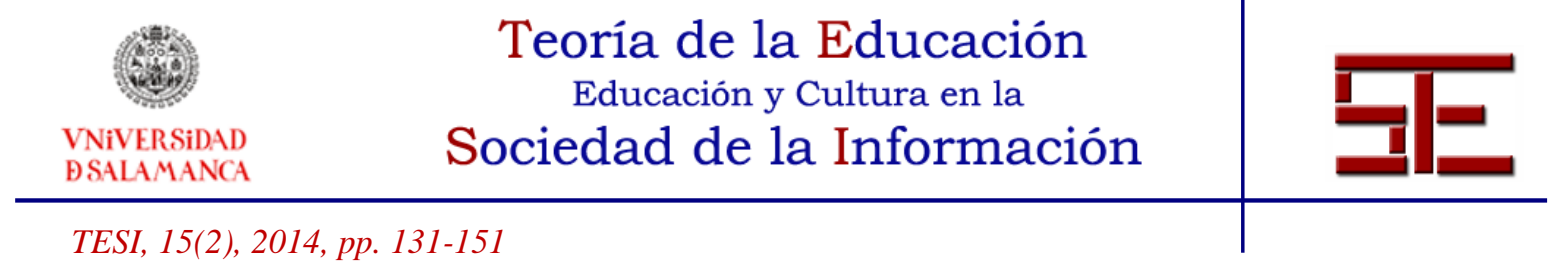

ubicuidad (Fundación Telefónica, 2012). La Era Digital, en permanente transformación, demanda mentes flexibles, personalidades fuertes y versátiles para adaptarse a los cambios y tiene como retos la mayor autonomía de los individuos, la renovación pedagógica que permita a los individuos participar activamente en su propio proceso de aprendizaje, una educación reflexiva como la que propone García Hoz (1988), en la que el docente es un guía del proceso valorativo que ha de realizar el propio alumno para llegar a adquirir un criterio objetivo y propio, que le haga capaz de tomar decisiones fundadas, legítimas y eficaces.

La tecnología que impera en estos momentos y la otra incipiente que cada vez se extiende más se convierten en un motivo de esperanza para poder implantar esta concepción personalizada de la educación. Las posibilidades que los nuevos servicios de Internet han abierto a la comunicación -muchos de ellos gratuitos y sencillos de manejar-, la facilidad en la difusión de ideas, la ruptura de las barreras geográficas y temporales, la democratización del conocimiento, las nuevas capacidades tecnológicas que permiten la absoluta personalización y experimentación, la novedosa filosofía que envuelve el uso de Internet asociado a la libertad del internauta, a la apertura al mundo, a la arquitectura de participación y reciprocidad global, las herramientas colaborativas y flexibles que han aparecido en torno a esta nueva generación de Internet... son todas razones que hacen posible hoy más que nunca una educación que forme seres íntegros, una educación personalizada, convivencial, integradora, abierta, reflexiva, crítica, exigente y alegre (Castellanos, 2013; Bernardo, 2011).

Las perspectivas tecnológicas de futuro han de apuntar a una atención al discente desde las diferentes dimensiones que lo integran en tanto que persona. Esta tecnología ha de permitir la articulación entre sincronía y asincronía, facilitando la libertad de elección atendiendo a la originalidad y distinción entre los estudiantes; la formación en nuevas capacidades y competencias, fomentando todo su potencial que defina a cada uno desde sus rasgos diferenciadores; y la "necesidad de crear redes de formación también como espacios de aprendizaje" (Gisbert, 2013, 57) que faciliten la sociabilidad del estudiante y así como la adquisición de "experiencias en cualquier área del desarrollo" (Benavides, 2004, 57).

\section{5.- CONCLUSIONES}

Dentro del trabajo de nuestro Grupo, tratando de profundizar en el concepto de educación personalizada, y explicitar algunas de sus múltiples aplicaciones pedagógicodidácticas, proponemos, de modo tentativo, que, "educar es ayudar a cada ser humano a establecer y mantener vínculos valiosos con la realidad".

Considerando que cada una de las palabras significativas del enunciado propuesto pretende ser exponente de una carga semántica profunda que pueda considerarse como un meristemo generador de nuevos conceptos y/o aplicaciones didácticas, utilizamos el

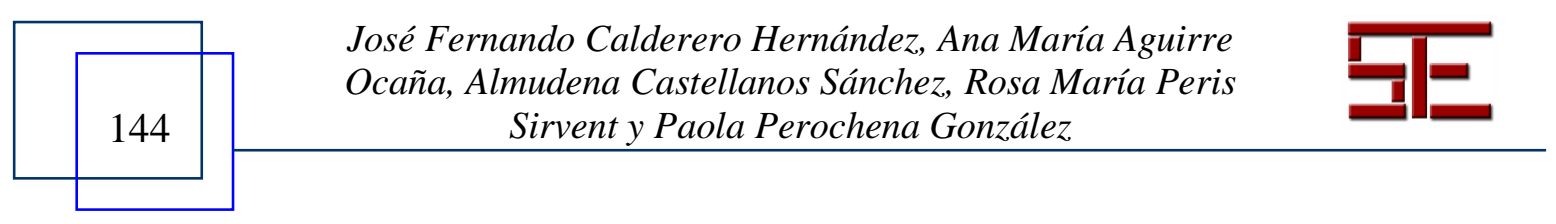




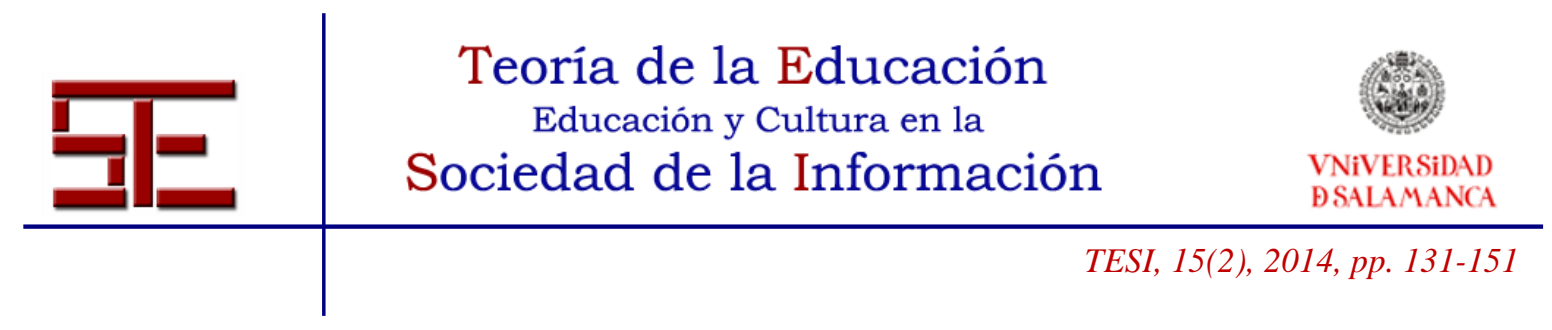

anterior enunciado como supuesto base para explicitar el alcance y limitaciones de esta nuestra inicial aportación.

Por tanto, como avance de futuros trabajos presentamos breve y parcialmente algunas de las posibles líneas de desarrollo de las ideas base de la definición propuesta.

Ayudar hace referencia a la consideración del educando como principal sujeto de su propia educación no sólo como sujeto paciente, sino, dependiendo de las edades y del grado de desarrollo, en gran medida agente. Trata de evitar que se piense en la persona como resultado irresponsable de los procesos a los que haya sido expuesta. Así se pretende que el estudiante sea el verdadero protagonista y responsable de su propio proceso de aprendizaje.

Cada nos centra en la singularidad de la persona; evitando considerar la educación como algo tan centrado en lo social, lo colectivo, que la persona se considere casi exclusivamente como un elemento del grupo. En particular debe evitarse toda contradicción, confrontación, entre lo "personal" y lo social ya que ambos aspectos, "individualidad" y "sociabilidad", son dos aspectos esenciales de cada ser humano y los aspectos sociales son tan relevantes que sin ellos no puede darse auténtica educación. Las dicotomías ayudan a comprender la realidad, pero el "ejercicio de vuelta a la unidad" es imprescindible para el verdadero progreso hacia el perfeccionamiento, el crecimiento personal, la mejora..., en definitiva, para el aprendizaje.

Vínculos se entiende en sentido amplio considerando todas las dimensiones de la persona humana: intelectual, afectiva, física, etc.; todos los canales: visual, auditivo, táctil, cogitativo, cenestésico, etc., y todos los lenguajes: escritos, orales, corporales, simbólicos, etc., son vínculos que ayudan a construir la identidad personal.

Establecer requiere el desarrollo de la capacidad de observación y atención, requisitos imprescindibles para poder "hacerse cargo" de todo aquello que se ofrece a la percepción humana; para ello es necesario desarrollar en grado suficiente los sentidos, externos e internos.

Mantener alude a la necesidad de adquirir hábitos operativos buenos - virtudes - sin los cuales educadores y educandos podrían conformarse con la mera contemplación de los valores universales del hombre sin influencia práctica en la conducta.

Valioso, entendido este término en el sentido más amplio posible; es decir, tanto aquello que puede ser considerado objetivamente valioso para cualquier ser humano reconocimiento de la dignidad personal, alimento, vivienda, etc.-, como lo que sólo será considerado de valor para algunos, como pueden ser un alto nivel intelectual, o físico, pragmático o artístico..., o lo que puede tener valor incluso para una sola persona.

Realidad, considerada tanto en los aspectos físicos como en los conceptuales, abstractos, virtuales, etc.; en suma, todo aquello que "es", o puede ser,

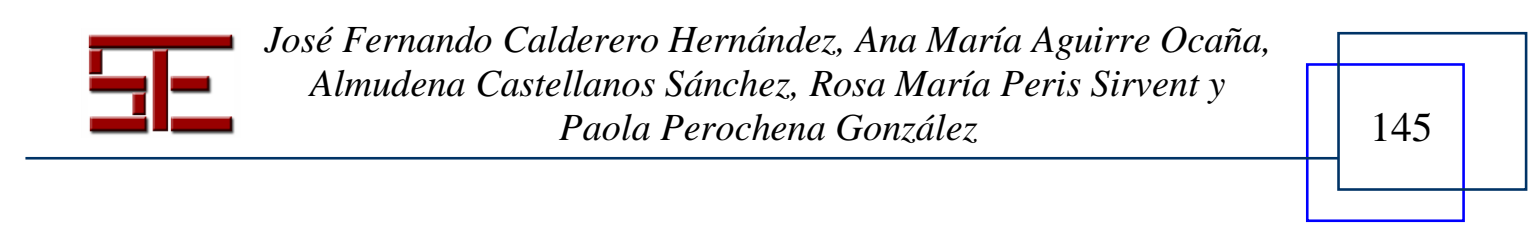




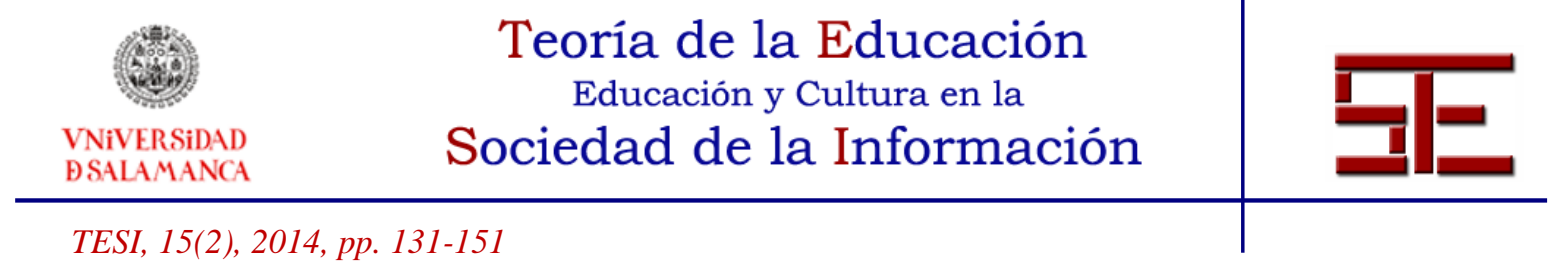

independientemente del grado de conocimiento que de ello se tenga. Cabría destacar la peculiar relación que se puede, y quizá se deba, establecer con la realidad aún no descubierta y que precisamente porque alguien se "ha interesado" en ella puede pasar a ser conocida; es decir, lo que algunos denominan impropiamente "existir". También debe considerarse la realidad no fácilmente cognoscible, o incluso la que quizá pueda ser incognoscible o no completamente cognoscible, por el ser humano. Puede comentarse un grave error de percepción, y por tanto de rigor intelectual, considerando sólo como real aquello que ha sido o puede ser asimilado y/o asumido por el género humano. De lo anterior se desprende la importancia de la creación de los vínculos, dada la capacidad del ser humano para transformar la realidad, hay algunas realidades que, de no ser por la interacción humana, no hubieran sido como son actualmente. Por estas razones se justifica la necesidad de educar en y para la libertad porque en la toma de decisiones que hacemos -en tanto que seres libres- somos capaces de destruir o construir, podemos mejorar o empeorar, enriquecer o empobrecer... aquello que nos rodea.

El objetivo central de este trabajo ha sido aportar una nueva aproximación al concepto de educación personalizada en la sociedad actual. Podemos concluir que esta nueva aportación se centra en el situar verdaderamente a la persona y -por tanto al estudianteen el centro del proceso educativo en tanto que posee anhelo de perfección y felicidad constitutivo de su ser personal.

Educación Personalizada supone una concepción muy amplia y aplicable a diversos sistemas y metodologías y su alcance supera el hecho de conseguir objetivos marcados en un currículo que -si bien son necesarios-, deben contribuir a la formación de todos y cada uno de los aspectos que conforman el ser personal de cada estudiante.

La personalización de la educación sí es atender a las necesidades personales de cada alumno; pero no sólo es eso, sobre todo, es concebir al estudiante en su dignidad y desde allí, planificar, ejecutar, guiar, orientar, evaluar... el proceso de enseñanzaaprendizaje de modo que ocurra un verdadero aprendizaje que será único para cada uno.

Las TIC pueden contribuir a la personalización en tanto que facilitan la configuración de los procesos para ajustarse a las necesidades de cada alumno. Pero el que un programa educativo se ajuste a las necesidades individuales no es la seña de identidad más importante en la personalización de los procesos educativos. En este sentido, el trabajo de Guerra (2013) señala que trabajar con ordenadores permite a los estudiantes entenderlos como un medio para conseguir un fin, permite descubrirse a uno mismo como inteligente y como un ser que ejerce su libertad para resolver problemas; y mucho más importante, las TIC "colaboran con la educación personalizada y facilitan la educación en valores" (Guerra, 2013, 103) trascendentes.

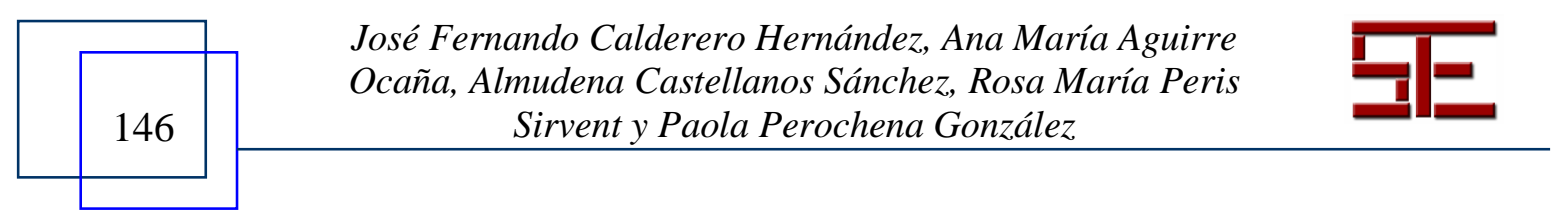




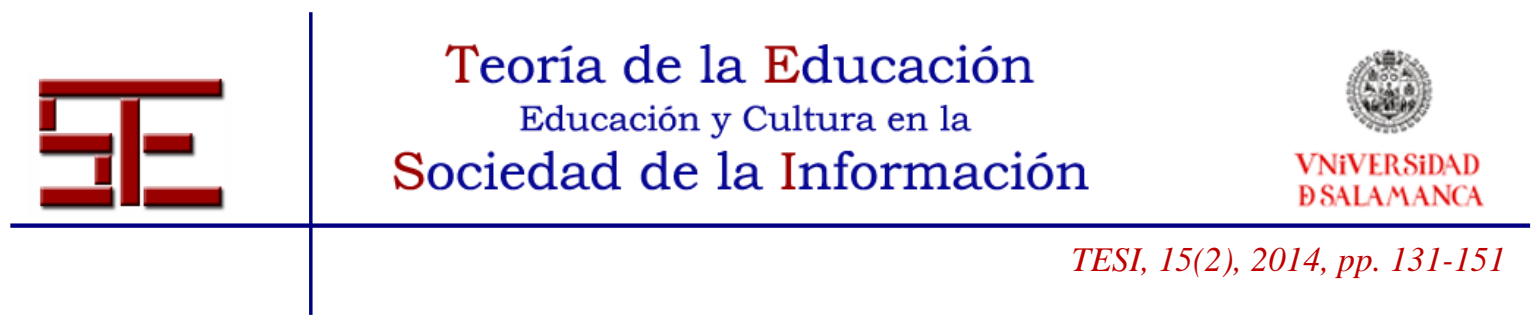

Los resultados obtenidos por Castellanos y Martínez (2013) apuntan que las herramientas TIC resultan motivadoras y pueden personalizar la educación en tanto que una de las ventajas de su uso es que responden a la dimensión social de la persona facilitando el trabajo en equipo en la universidad.

Las notas propias de la persona derivan necesariamente a considerar la creatividad como una condición sine qua non de la educación. Considerar la capacidad del estudiante para transformar la realidad desde su libertad y voluntad propias sitúa la creatividad como uno de los pilares fundamentales de la educación personalizada. Esta cuestión será una prospectiva para trabajos futuros del Grupo de Investigación.

A modo de nota final, la intención de este trabajo no es solucionar definitivamente la cuestión sobre la definición del concepto. Se pretendió abrir -o quizá retomar- la concepción de la educación personalizada para que sea objeto de estudio en el ámbito científico y ofrecer un punto de partida para su puesta en práctica y fundamentación teórica en la Sociedad Digital en la que nos encontramos.

\section{6.- REFERENCIAS}

Adell, J. \& Castañeda, L. (2010). Los Entornos Personales de Aprendizaje (PLEs): una nueva manera de entender el aprendizaje. En R. Roig. \& M. Fiorucci (Eds.), Claves para la investigación en innovación y calidad educativas. La integración de las Tecnologías de la Información y la Comunicación y la Interculturalidad en las aulas. Stumenti di ricerca per l'innovaziones e la qualità in ámbito educativo. La Tecnologie dell'informazione e della Comunicaziones e l'interculturalità nella scuola. Alcoy: Marfil-Roma TRE Universita degli studi.

Adell, J. \& Castañeda, L. (2012). Tecnologías emergentes, ¿pedagogías emergentes? En J. Hernández, M. Pennesi, D. Sobrino y A. Vázquez (coords.) Tendencias emergentes en educación con TIC. Barcelona: Asociación Espiral, Educación y Tecnología.

Archideo, L. B. (1996). Tesauro en Filosofía de la Educación/Philosophy of Education Thesaurus. Buenos Aires: CIAFIC.

Ayala, J. (2006). Persona humana y autorrealización. Philosophy of Education, 4, 7-12. The Proceedings of the Twenty-First World Congress of Philosophy.

Benavides (2004). La educación personalizada como un recurso que promueve mejores logros escolares e interpersonales en niños con problemas familiares afectivos del primer año de básica, estudio de casos realizado en el Liceo Bilingüe Hontanar. Tesis. Universidad Politécnica Salesiana, Ecuador.

Bernal, A. (1993). Carácter singularizador del estilo de la educación personalizada. Cuadernos de Pensamiento, 8, 51-70.

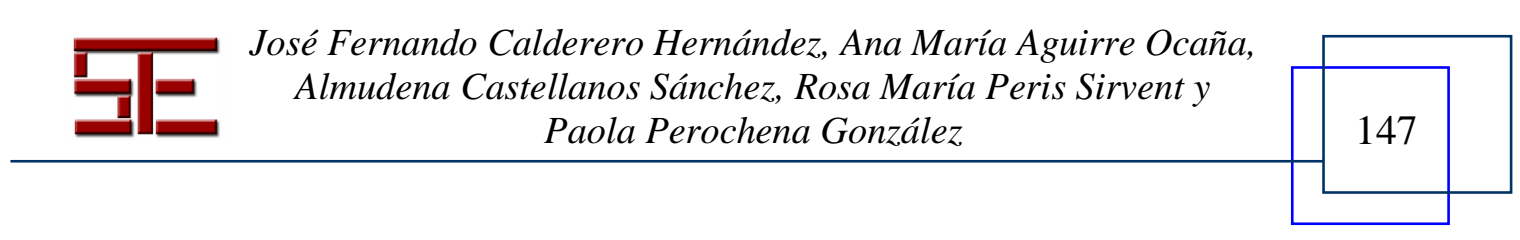




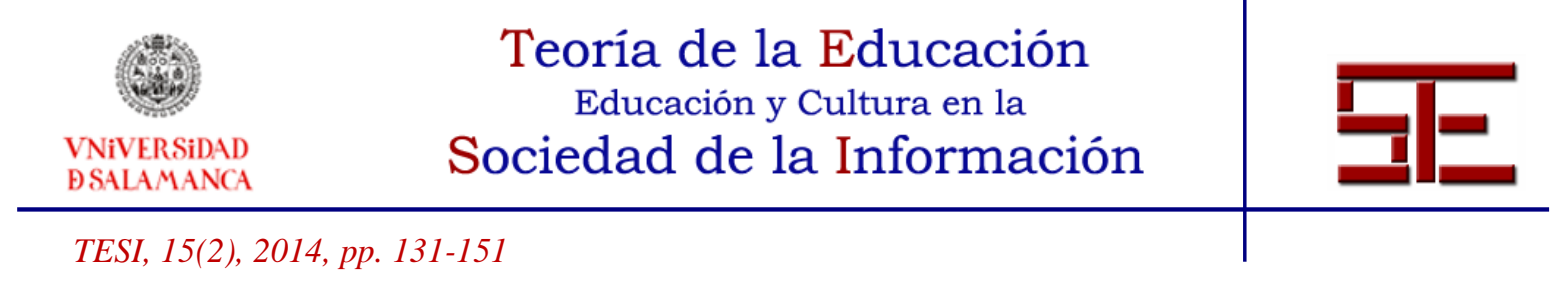

Bernardini, A. \& Soto, J. A. (1984). La educación actual en sus fuentes filosóficas. San José: EUNED.

Bernardo, J. (coord.) (2011). Educación personalizada: principios, técnicas y recursos. Madrid: Síntesis.

Bowen, J. \& Hobson, P. R. (1979). Teorías de la Educación. Innovaciones importantes en el pensamiento educativo. Mexico: Limusa.

Castellanos, A. (2013). Aplicación y análisis de la Educación Personalizada en entornos virtuales de aprendizaje con estudiantes del Grado Maestro de Educación Primaria. Memoria para optar al título de Doctor. Universidad Nacional de Educación a Distancia UNED. Madrid, España.

Castellanos, A. \& Martínez, A. (2013). Trabajo en equipo con Google Drive en la universidad online. Revista Innovación Educativa, 13 (63), 75-94.

Consejo Superior de Investigaciones Científicas (1981). La Calidad de la educación: exigencias científicas y condicionamientos individuales y sociales. Madrid: CSIC-CSIC Press.

Cortina, A. (2003). El vigor de los valores morales para la convivencia. La convivencia en los centros escolares como factor de calidad. Construir la convivencia. Madrid: Ministerio de Educación, Cultura y Deporte.

Daura, F. T. (2012). La asesoría académica universitaria: un espacio propicio para la promoción del aprendizaje autorregulado. Revista de Orientación Educacional, 25 (47), 49-63.

Domínguez, X. M. (2002). Para ser persona. Madrid: Fundación Emmanuel Mounier.

Dottrens, R. (1973). La Enseñanza Individualizada. Robert. Buenos Aires: Kapelusz.

Fundación Telefónica (2012). Aprender con tecnología. Investigación internacional sobre modelos educativos de futuro. Madrid: Ariel.

García, J. G. \& Álvarez, G. M. (2008). Reconfiguración como sujetos de comunicación: implicaciones para los ambientes virtuales con fines educativos. Revista de Universidad y Sociedad del Conocimiento, RUSC, 5 (2), 4-16.

García Hoz, V. (1970). Educación personalizada. Madrid. Instituto de Pedagogía del C.S.I.C. Madrid: C.S.I.C.

García Hoz, V. (1988). Educación personalizada. Madrid: Rialp.

García Hoz, V. (1993). Introducción general a una pedagogía de la persona. En Tratado de la Educación Personalizada. Madrid: Rialp.

García Hoz, V., Bernal, A., Cervera, J., Lomas, C., Losada, I., Navarro, M., Pérez Juste,

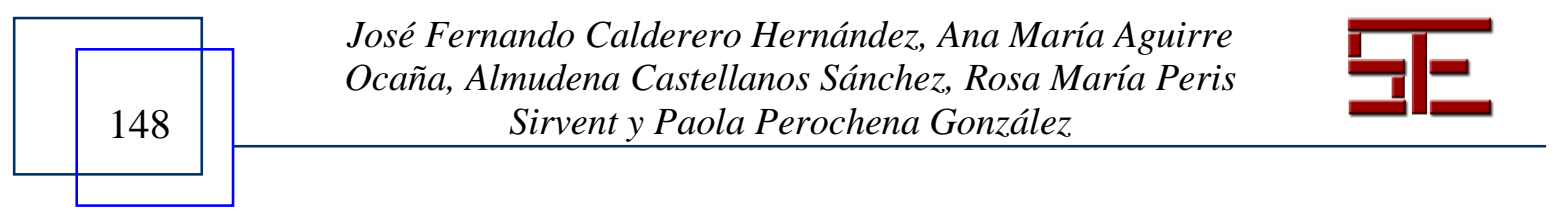




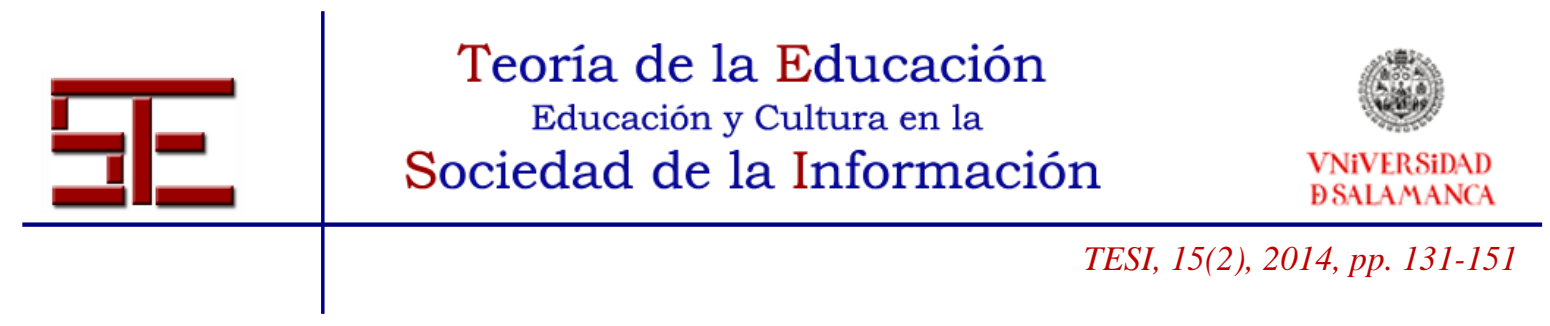

R. (1993). Tratado de educación personalizada. La educación en el nivel primario. Madrid: Ediciones Rialp.

George Mason University (2013). Hugth T. Sockett. [Consultado el día 21 de enero de 2014]. Recuperado de http://pia.gmu.edu/people/hsockett.

Gimeno, J. (2000). La construcción del discurso acerca de la diversidad y sus causas. En Gavilán, P. et al. (1ª Ed.), Atención a la diversidad, (pp.11-36). Barcelona: Graó.

Gisbert, M. M. (2013). Nuevos Escenarios para los aprendices digitales en la universidad. Aloma: Revista de Psicologia, Ciències de l'Educació i de l'Esport, 31 (1), 55-64.

González, T. \& Rodríguez, M. (2010). El valor añadido de las buenas prácticas con TIC en los centros educativos. Revista Electrónica Teoría de la Educación: Educación y Cultura en la Sociedad de la Información, 11 (1), 262-282.

Guerra, M. S. (2013). La tecnología y la educación personalizada. Teoría y práctica. Buenos Aires: Alfaomega, Grupo Editor Argentino.

Gutiérrez, I., Castañeda, L. \& Serrano, J. L. (2013). Más allá de la Flipped Classroom: "dar la vuelta a la clase" con materiales creados por los alumnos. II Congreso Inter-nacional Educación Mediática y Competencia Digital. Barcelona, España.

Hamdan, N., McKnight, P., McKnight, K. \& Arfstrom, K. (2013). A white paper based on the literature review titled A Review of flipped learning. Pearson. Flipped Learning Network. Recuperado de http://researchnetwork.pearson.com/wpcontent/uploads/WhitePaper_FlippedLearning.pdf.

Harzem, P. (1996). On the parting of our days from Fred Simmons Keller: sketches for a portrait of a great man. Mexican Journal of Behavior Analysis, 1, 5-12.

Hernández, M. G. \& Ramos, J. M. (1996). Un modelo tutorial universitario. Revista Complutense de Educación, 7 (1), 51-68.

Hofstetter, R. \& Schneuwly, S. (2009). Knowledge for teaching and knowledge to teach: two contrasting figures of New Education: Claparède and Vygotsky. Pedagogía Histórica: Revista Internacional de Historia de la Educación, 5 (4), 605-629.

Hugth, S. (2011). El conocimiento y la virtud en la enseñanza y el Aprendizaje de las Disposiciones. London: Kindle Edition.

Keller, F. S. \& Sherman, J. G. (1982). The PSI Handbook: Essays on Personalized Instruction. Lawrence. Kansas: TRI Publications.

Ley Orgánica 8/2013, de 9 de diciembre, para la mejora de la calidad educativa (LOMCE). Boletín Oficial del Estado (España), de 10 de diciembre de 2013.

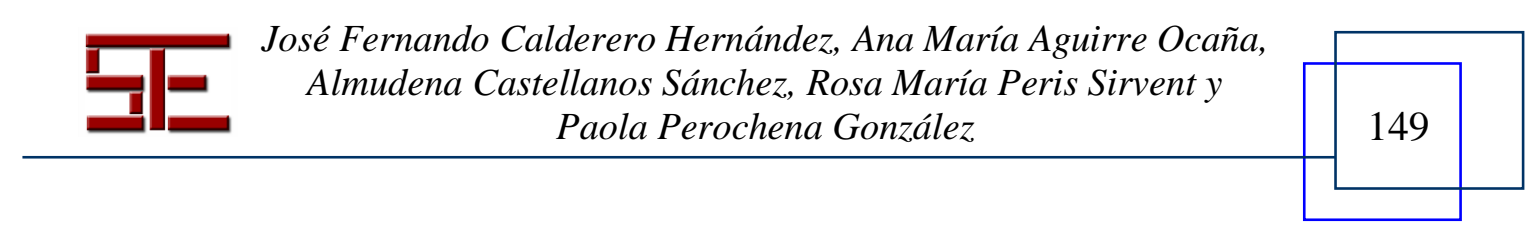




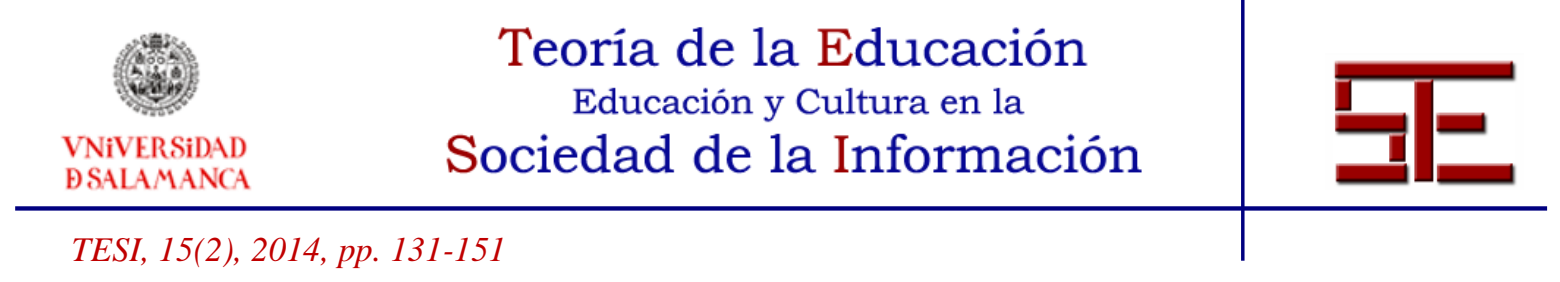

Maritain, J. (1965). La educación en este momento crucial. Buenos Aires: Desclée de Brouwer.

Medina, R. (1989). La educación como un proceso de personalización en una situación social. Tratado de la Educación Personalizada, vol. 2. Madrid: Rialp.

Nuttin, J. (1972). El psicoanálisis y la concepción espiritualista del hombre. Buenos Aireas: EUDEBA.

Pereira de Gómez, M. N. (1981). Educación Personalizada: Un proyecto pedagógico de Pierre Faure. México: Trillas.

Pradas, S. (2001). La integración de las nuevas tecnologías en la educación personalizada en la red. En A. Sipán et al., Educar para la diversidad en el siglo XXI (pp. 581-586). Zaragoza: Mira.

Pujolàs, P. (2010). No es inclusión todo lo que se dice que es. Aula de Innovación Educativa, 191, 38-41.

Torres, G. (2011). Evaluación en educación: necesidad de políticas institucionales con visión pedagógica. Praxis \& Saber, 2 (4), 219-239.

Uyeda, S. M., Luft, J. A., Madden, J., Washburne, J. \& Brigham, L. A. (2003). Transferring and Constructing Knowledge: Designing an STC Based Teacher Workshop. Journal of geoscience education, 51 (5), 484-489.

Valverde, J. M. (1993). El concepto de persona en la educación personalizada. Revista Educación, 17 (1), 87-93.

Van der Ploeg, P. (2013). The Dalton Plan: recycling in the guise of innovation. Pedagogía Histórica: Revista Internacional de Historia de la Educación, 49 (3), 314-329.

Vázquez, S. M. (2000). II Encuentro Nacional de Docentes Católicos Universitario. La Persona y el fin de la Educación. [Consultado el día 21 de enero de 2014]. Publicación on-line, Recuperado de: http://issuu.com/shikomaru/docs/vazquez_persona_y_fin_de_la_educacion

Vázquez, S. M. (2009). Motivación y Voluntad. Revista de psicología, 27 (2), 185-212.

Walsh, K. (2013). Gathering Evidence that Flipping the Classroom can Enhance Learning Outcomes. Recuperado de http://www.emergingedtech.com/2013/03/ gathering-evidencethat-flipping-the-classroom-can-enhance-learning-outcomes/.

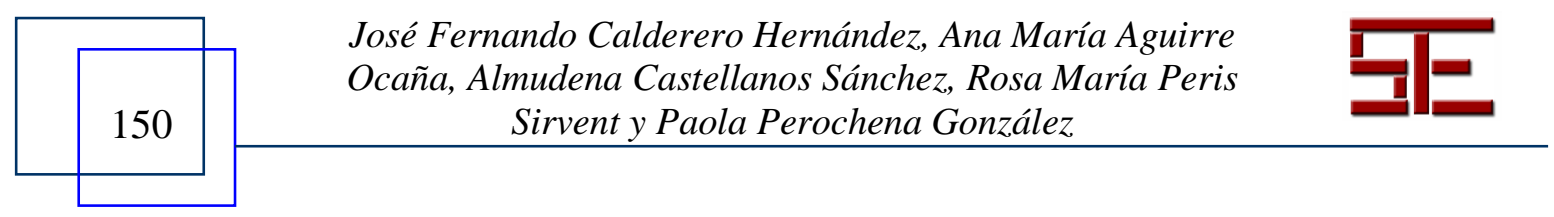




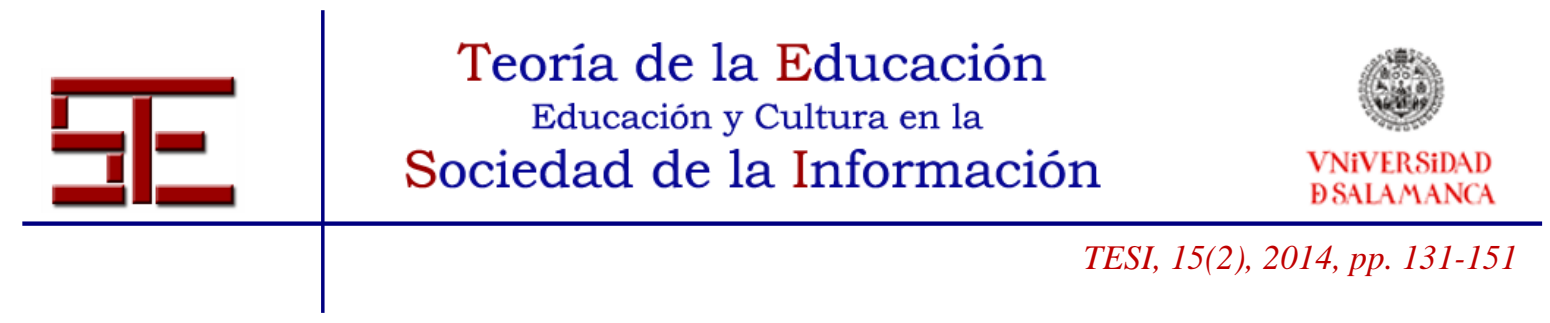

Para citar el presente artículo puede utilizar la siguiente referencia:

Calderero Hernández, J. F., Aguirre Ocaña, A. M., Castellanos Sánchez, A., Peris Sirvent, R. M. y Perochena González, P. (2014). Una nueva aproximación al concepto de educación personalizada y su relación con las TIC. Revista Teoría de la Educación: Educación y Cultura en la Sociedad de la Información. 15(2), 131-150 [Fecha de consulta: dd/mm/aaaa].

http://campus.usal.es/ revistas_trabajo/index.php/revistatesi/article/view/11890

José Fernando Calderero Hernández, Ana María Aguirre Ocaña, Almudena Castellanos Sánchez, Rosa María Peris Sirvent y Paola Perochena González. 